\title{
Development and Realization an Android Based Software to Support Feasibility Study of Harmonics Mitigation
}

\author{
Chairul Gagarin Irianto, Haposan Yoga Pradika Napitupulu, and Maulasukma Widjaja \\ Department of Electrical Engineering \\ Universitas Trisakti, Jakarta, Indonesia \\ chairul_irianto@trisakti.ac.id, haposan.ypn@outlook.com,maula@trisakti.ac.id
}

\begin{abstract}
Harmonic distortion is not a new phenomenon and has several detrimental impacts on electrical power system. Therefore, installation of harmonic filter is needed to mitigate and suppress it. Most PC based software have been developed to conduct feasibility study such as OrCAD, ETAP, DigSILENT, PSIM, etc. Unfortunately, all of them only provide the harmonics data of power electronics from their library which can lead the simulation into inaccurate result since it will produce a wide range of deviation until $179,8 \%$ in the simulation of last research in reference [16].Meanwhile conduct simulation using measured data from real condition of power system, comparing the harmonics distortion occurred to the standard, and filter's parameter calculation can't be conducted on those software yet. This research proposes an Android based software namely HFMS Usakti, an application to conduct harmonics distortion feasibility study more accurate and efficient. HFMS Usakti consists of three main steps: automatically check and compare harmonics distortion occurred according to the Standard IEEE $519^{\mathrm{TM}}-2014$, automatically calculate the parameter of filters, and automatically simulate harmonics distortion after filtering. This research consists of three main aspects: application design, development, and testing. In the end, HFMS Usakti has been validated using PSIM software and experimental testing. The result shows that HFMS Usakti works properly and be able to significantly eliminate the deviation between the measured data and simulation value of harmonics distortion before filtering from $179,8 \%$ to $0 \%$.
\end{abstract}

Keywords: Android, Harmonics, Mobile application, Passive filters, Software

\section{Introduction}

Harmonics distortion is not a new phenomenon on electrical power system. It is caused by non-linier devices in the power system such as power electronics devices, inverter, converter andcapacitor bank. This phenomenon occurred because some waves in the multiple frequencies from its fundamental frequency emerge in power system [1]. Harmonics distortion has several effects to the electrical devices, such as transformer heating which is the temperature of winding and the temperature iron core of transformer will increase when the transformer is given a frequency outside of its fundamental frequency Other effects such as electrical machine heating, capacitor heating, also cable heating will occur [2] [3] [4].

Nowadays, installing passive filters into power system is one of many ways to mitigate and suppress harmonics distortion. The harmonics filters which are currently used to mitigate harmonics distortion are single tuned filter, double tuned filter, damped-type double tuned filter, and c-type filter. Single tuned filter is the most commonly used filter to suppress one harmonic order, not only suppressing harmonics distortion but also maintaining the power factor (PF) at desired value [5] [6] [7] [8]. Double-tuned filter is like two parallel single tuned filters which can suppress two harmonic orders, It is more economical to be produced because the cost of double tuned filter is less than two parallel single tuned filters [9] [10]. Damped-type double tuned filter is developed from double tuned filter and has a resistor as a damper to prevent network and the filter from harsh condition when the filter and the network are conjugated [11]. Furthermore, c-type filter is a broadband filter, it is suitable for suppressing harmonics distortion generated by converter [12] [13].

Received: May $8^{\text {th }}, 2020$. Accepted: June $15^{\text {th }}, 2021$ DOI: 10.15676/ijeei.2020.13.2.4 
Before installing the filter into power system, a feasibility study using analytical software needs to be conducted to know the effect of the filter when it is installed into power system. Some analytical software has been developed to study the harmonics phenomenon, for example, Matlab, a software most commonly used by professional engineers and scientists based on high level programming and mathematic equation. On the other hand, there is a software circuit-based such as OrCAD and PSIM that address the problem from electrical circuit. Hereafter, there are software programsbased on electrical network such as ETAP, CYME and DigSILENT that address the problem from electrical network in power system.

Reference [14] has conducted a study of analysis and treatment of harmonic in power network based on ETAP, but the simulation result of harmonics order before treatment is not entirely the same with the measured data. Also, reference [15] has conducted a study about designing the optimum filter for mitigating harmonics distortion in traction substation of electric train, but the result of the simulation before filtering is different with the measured data Moreover, reference [16] also conducted a study of harmonics distortion at C K Pithwalla college of Engineering and Technology Surat Gujarat, but the result of the simulation before filtering cannot represent the measured data.

This is because of no harmonics library in the software from the rectifier brand which is used in the field. Thus, the software programs which commonly used for the feasibility study only provide the harmonics data of power electronics from their library and do not represent the real harmonics occurrence from power system. A study without measured data that represent real condition on power system will produce less accurate result and the calculation of filter parameters will be incorrect. This condition can lead the filter doesn't suppress harmonics distortion at tuned frequency on power system.

This paper contributes the development of a new Android based software, Harmonics Filter Modelling Software (HFMS) Usakti which is particularly capable to simulate harmonics distortion based on measurement data of harmonics current and harmonics voltage in the power system, it helps engineer to make a feasibility study more accurately using measured data from real condition on power system. HFMS Usakti is also adequate to compare the measurement data with the harmonics limit based on standard IEEE 519 ${ }^{\mathrm{TM}}-2014$. Further, HFMS Usakti is suitable to calculate four kinds of harmonics passive filters such as single tuned filter, double tuned filter, damped-type double tuned filter and c-type filter automatically based on measurement data. Last, HFMS Usakti is able to simulate the effect after the filter is installed into the power system.

\section{Feasibility Study Conducted at Present Day (Using Common Software such as ETAP software, MATLAB software)}

Several studies have conducted the feasibility study and mitigation of harmonics distortion in power network using common software such as ETAP software, MATLAB software and etc. Here are some examples of feasibility study which conducted at present day with inefficient way and inaccurate results.

\section{A. Feasibility Study in Railway Network at Huozhou}

Reference [14] conducted a study of analysis and treatment of harmonic in railway power network in Huozhou based on ETAP software. The general method of study analysis can be described as: The first one, researcher need to draw the network diagram of power distribution, it will be used to design in ETAP software later. Secondly, researcher has to measure the harmonics distortion and other parameters in specific bus (PCC) that want to be installed harmonics filter later, this data will be used to design in ETAP software. Thirdly, after collecting data, researcher has to compare the harmonics occurred to the standard manually and make a specific note to the harmonics order that out of standard.

Not only that, researcher need to draw and design the railway power network and input all parameters in ETAP software and make some adjustments since ETAP software is not capable to modify the harmonics distortion data so that the simulation results are not exactly the same as the measurement results. Then, researcher need to conduct simulation using ETAP software to 
make sure the result is nearly the same with the data they collected before. Further, researcher has to calculate the filter parameter manually. Then, jump to the ETAP software again to add the design of filter and input the filter parameter to the design. After all long way, researcher can make a simulation of power network after filtering.

This feasibility method consists unnecessary steps and takes inefficient way. Moreover, the result of simulation before filtering is not the same with the measured data. It can lead researcher to the inaccurate result of study. Table 1 below shows the comparison between measured data and simulation value of harmonics current [14]. Table 2 below shows the comparison between measured data and simulation value of harmonics voltage [14].

Table 1. Comparison between Measured Data and Simulation of Harmonics Current [14]

\begin{tabular}{|l|c|c|c|c|c|c|c|}
\hline \multirow{2}{*}{ Index } & \multicolumn{7}{|c|}{ Dominant Harmonics Current $(\mathrm{A})$} \\
\cline { 2 - 9 } & $\mathrm{h}_{3}$ & $\mathrm{~h}_{5}$ & $\mathrm{~h}_{7}$ & $\mathrm{~h}_{11}$ & $\mathrm{~h}_{13}$ & $\mathrm{~h}_{17}$ & $\mathrm{~h}_{19}$ \\
\hline Measured data & 9.71 & 17.62 & 13.16 & 5.17 & 3.75 & 1.81 & 1.45 \\
\hline $\begin{array}{l}\text { Simulation value in ETAP } \\
\text { software }\end{array}$ & 9.58 & 17.62 & 12.89 & 5.08 & 3.79 & 1.89 & 1.37 \\
\hline $\begin{array}{l}\text { Deviation between Measured } \\
\text { data VS Simulation value }\end{array}$ & $\begin{array}{c}1.34 \\
\%\end{array}$ & $\begin{array}{c}0.00 \\
\%\end{array}$ & $\begin{array}{c}2.05 \\
\%\end{array}$ & $\begin{array}{c}1.74 \\
\%\end{array}$ & $\begin{array}{c}1.07 \\
\%\end{array}$ & $\begin{array}{c}4.42 \\
\%\end{array}$ & $\begin{array}{c}5.52 \\
\%\end{array}$ \\
\hline
\end{tabular}

Table 2. Comparison between Measured Data and Simulation of Harmonics Voltage [14]

\begin{tabular}{|l|c|c|c|c|c|c|c|}
\hline \multirow{2}{*}{ Index } & \multicolumn{7}{|c|}{ Dominant Harmonics Voltage } \\
\cline { 2 - 8 } & $\mathrm{h}_{3}$ & $\mathrm{~h}_{5}$ & $\mathrm{~h}_{7}$ & $\mathrm{~h}_{11}$ & $\mathrm{~h}_{13}$ & $\mathrm{~h}_{17}$ & $\mathrm{~h}_{19}$ \\
\hline Measured data & 1.00 & 5.11 & 4.50 & 3.01 & 1.91 & 1.12 & 0.81 \\
\hline $\begin{array}{l}\text { Simulation value in ETAP } \\
\text { software }\end{array}$ & 1.05 & 4.91 & 4.37 & 3.07 & 1.81 & 1.07 & 0.75 \\
\hline $\begin{array}{l}\text { Deviation between } \\
\text { Measured data VS } \\
\text { Simulation value }\end{array}$ & $\begin{array}{c}5.00 \\
\%\end{array}$ & $\begin{array}{c}3.91 \\
\%\end{array}$ & $\begin{array}{c}2.89 \\
\%\end{array}$ & $\begin{array}{c}1.99 \\
\%\end{array}$ & $\begin{array}{c}5.24 \\
\%\end{array}$ & $\begin{array}{c}4.46 \\
\%\end{array}$ & $7.41 \%$ \\
\hline
\end{tabular}

\section{B. Feasibility Study in Traction Station in Pasar Minggu Station}

Reference [15] also conducted feasibility study using ETAP software in order to design an optimum filter to mitigate harmonics distortion in traction station of electric train in Pasar Minggu station, Jakarta. The method used in this study is similar with the reference [14]. Further, the measured data and simulation value are not entirely the same, so that it can lead the feasibility study to the inaccurate results. Table 3 below shows the comparison between measured data and simulation value of total harmonics distortion current [15].

Table 3. Comparison between Measured Data and Simulation of Harmonics Current [15]

\begin{tabular}{|l|c|c|c|c|c|c|c|}
\hline \multirow{2}{*}{ Index } & \multicolumn{7}{c|}{ THD-i (\%) } \\
\cline { 2 - 8 } & $\mathrm{D}_{1}$ & $\mathrm{D}_{2}$ & $\mathrm{D}_{3}$ & $\mathrm{D}_{4}$ & $\mathrm{D}_{5}$ & $\mathrm{D}_{6}$ & $\mathrm{D}_{7}$ \\
\hline Measured data & 47.33 & 46.29 & 52.47 & 51.67 & 39.91 & 63.38 & 42.01 \\
\hline $\begin{array}{l}\text { Simulation value in ETAP } \\
\text { software }\end{array}$ & 43.36 & 41.47 & 47.95 & 47.15 & 33.04 & 60.13 & 33.76 \\
\hline $\begin{array}{l}\text { Deviation between } \\
\text { Measured data VS } \\
\text { Simulation value }\end{array}$ & $8.39 \%$ & $10.41 \%$ & $\begin{array}{c}8.61 \\
\%\end{array}$ & $\begin{array}{c}8.75 \\
\%\end{array}$ & $\begin{array}{c}17.21 \\
\%\end{array}$ & $\begin{array}{c}5.13 \\
\%\end{array}$ & $19.64 \%$ \\
\hline
\end{tabular}

\section{Feasibility Study at C K Pithwalla college of Engineering and Technology Surat Gujarat}

Reference [16] also conducted feasibility study using MATLAB software. The research was conducted at C K Pithwalla college of Engineering and Technology Surat Gujarat and has similar methodology research with reference [14] and [15].The difference between reference 
[16] and reference [14] [15] is in the software to make simulation. Which in reference [16] used MATLAB software to conduct simulation, whilst reference [14] and [15] used ETAP software.

The simulation result in reference [16] using MATLAB software cannot represent the measured data from non-linear loadsat C K Pithwalla college of Engineering and Technology Surat Gujarat. This condition can lead the feasibility study into inaccurate results. Table 4 below shows the comparison between measured data and simulation value of total harmonics distortion current and total harmonics distortion voltage at $\mathrm{C} \mathrm{K}$ Pithwalla college of Engineering and Technology Surat Gujarat [16].

Table 4. Comparison between Measured Data and Simulation of Harmonics Current [16]

\begin{tabular}{|l|c|c|}
\hline \multicolumn{1}{|c|}{ Index } & THD-i (\%) & THD-v (\%) \\
\hline Measured data & 67.44 & 2.13 \\
\hline $\begin{array}{l}\text { Simulation value in MATLAB } \\
\text { software }\end{array}$ & 30.40 & 5.96 \\
\hline $\begin{array}{l}\text { Deviation between Measured data } \\
\text { VS Simulation value }\end{array}$ & $54.92 \%$ & $179.8 \%$ \\
\hline
\end{tabular}

In connection with these studies above, the research in this paper aims to develop an Android based software to help researcher in order to conduct feasibility study more accurate and efficient. Which HFMS Usakti was designed consists of five easy steps: input measured data from power system, automatically check and compare harmonics distortion occurred according to the Standard IEEE 519 ${ }^{\mathrm{TM}}-2014$, choose harmonics filter which want to be installed, automatically calculate the parameter of filters, and automatically simulate harmonics distortion after filtering. To that aim, this paper consists of three main aspects: application design, development, and testing.

\section{Proposed Application}

The proposed application is based on Android platform, it is considered because Android is an open source software and this operating system is used by a lot of people. Because of HFMS Usakti is developed based on Android platform, so that HFMS Usakti can be installed and used in Android mobile devices.

\section{A. Application Design of HFMS Usakti}

According to the chapter 2 above, current feasibility study can be represented as shown in Figure 1.

From the current harmonics feasibility sequence in Figure 1 indicates two matters which can lead the feasibility study into inaccurate result and inefficient way. Firstly, inaccurate result can be happen because of the simulation before filtering does not capable to simulate the exact number of measured data which happen in the step number 4 and 5, like shown in Table 1, Table 2 and Table 3 that have wide range of deviation.

Secondly, there are unnecessary steps because the feasibility study is not conducted in single software for example: manually compare the harmonics distortion to the standard, manually calculate harmonics filter, manually input the filter's parameters to the software, etc. So that, we proposed an application to tackle those issues with activity diagram as shown in Figure 2. The feasibility study can be conducted in single software, it is hoped also to minimize the human error. 


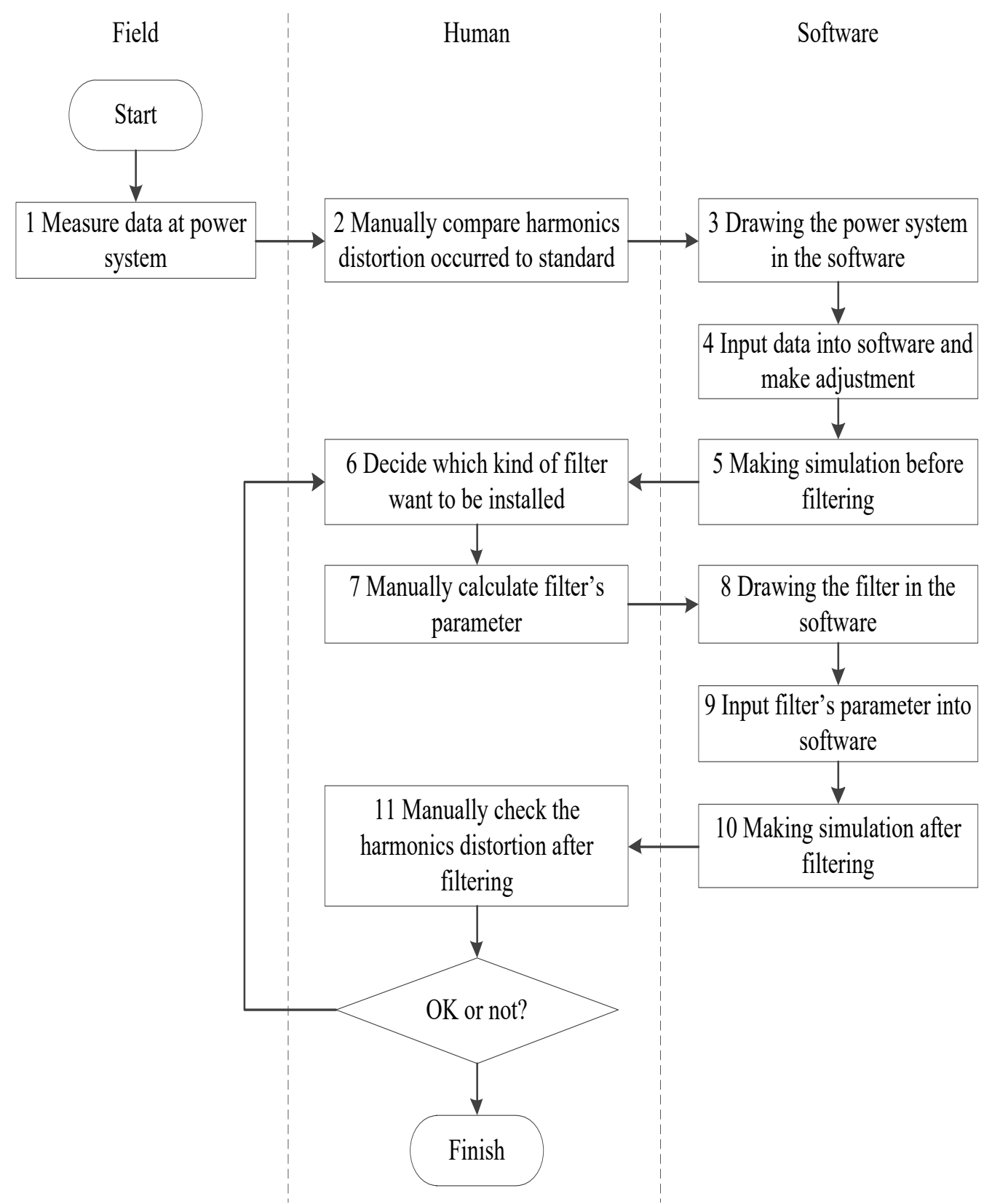

Figure 1. Current Feasibility Study 


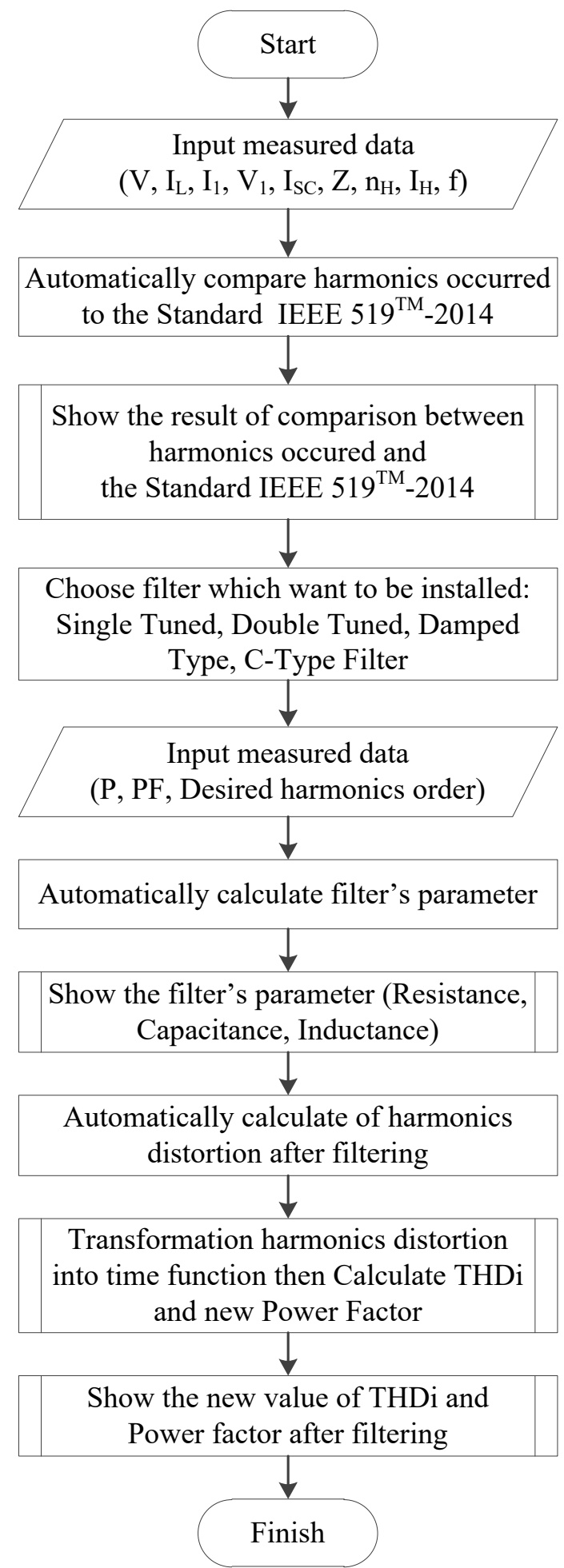

Figure 2. Activity Diagram of Proposed Software HFMS Usakti 


\section{B. Development of HFMS Usakti}

From the activity diagram above, the development of HFMS Usakti consists of three main steps of use that can be described below:

\section{1) Checking the harmonic measured data and comparing with IEEE $519^{T M}-2014$}

To use the application, engineer must collect measured parameter from Point of Common Coupling (PCC) on their power system such as fundamental current, fundamental voltage, working voltage, fundamental frequency, short circuit current, amplitude of harmonics current in each order and amplitude of harmonics voltage in each order. Those measured data can be collected from PCC on their power system using measurement devices such as Fluke Quality Analyzer, Hioki Power Analyzer, etc. The method of collecting data is not discussed in here The main HFMS Usakti interface of input measured data can be seen in Figure 3.a.

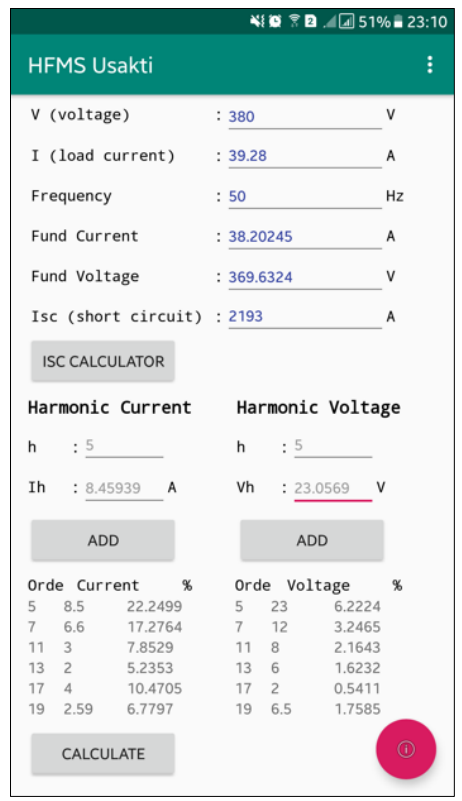

(a)

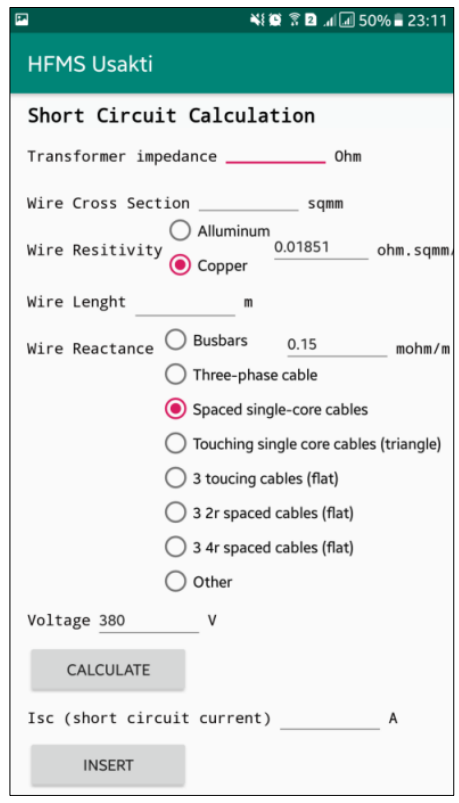

(b)

Figure 3. HFMS Usakti Interface. (a) Input Measured Data. (b) Short Circuit Calculation

After all measured parameters have been collected; inputthem into HFMS Usakti and press "Calculate" button as shown in Figure 3.a above. HFMS Usakti will reveal the comparison between measured data and harmonics limit based on standard IEEE $519^{\mathrm{TM}}-2014$, as shown in Figure 3. When harmonics current meets the standard, it will be marked as "OK" and if they are out of standard, it will be marked as "Bad". This way, HFMS Usakti makes easier and quicker for engineer to determine whether their power system is in good condition or not.HFMS Usakti also provides short circuit current calculation by clicking "Isc Calculator" button, new page will appear as shown in Figure 2.b."Isc Calculator" feature has a function to calculate short circuit current at PCC. This short circuit current is used along with load current to determine in which categories of harmonics distortion limits in the standard IEEE $519^{\mathrm{TM}}-2014$ [17].

$$
\begin{aligned}
& I_{h}(h)=\sum_{i=1}^{n} \sqrt{2} i_{i} \sin \left(2 h_{i} f \pi t\right) \\
& \mathrm{X}(\omega)=\Delta \sum_{n=0}^{N-1} x(t) e^{-j \omega t}
\end{aligned}
$$

HFMS Usakti is also able to show the comparison between waveform of harmonic measured data and the original when "Current Waveform" button is pressed. It can be seen in Figure 4.a, this function is based on Equation (1), where red line shows the harmonics waveform and green line shows the original waveform. HFMS is also proper in present the amplitude for each 
Chairul Gagarin Irianto, et al.

harmonic order by pressing "Current Frequency" button as shown in Figure 4.b, this function is based on Equation (2).

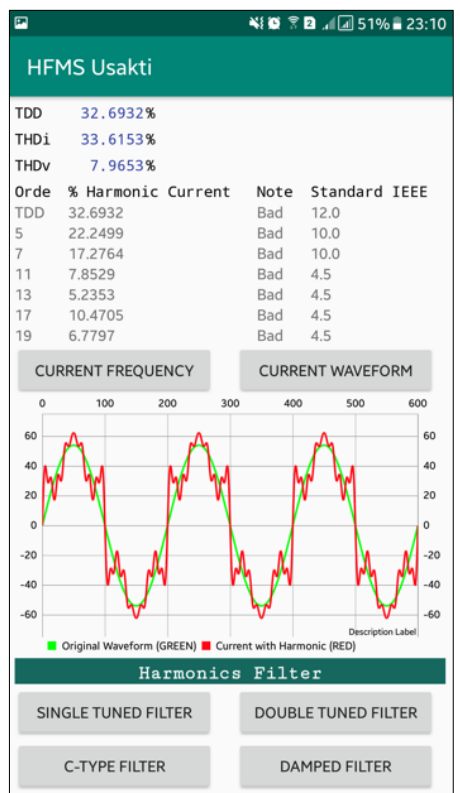

(a)

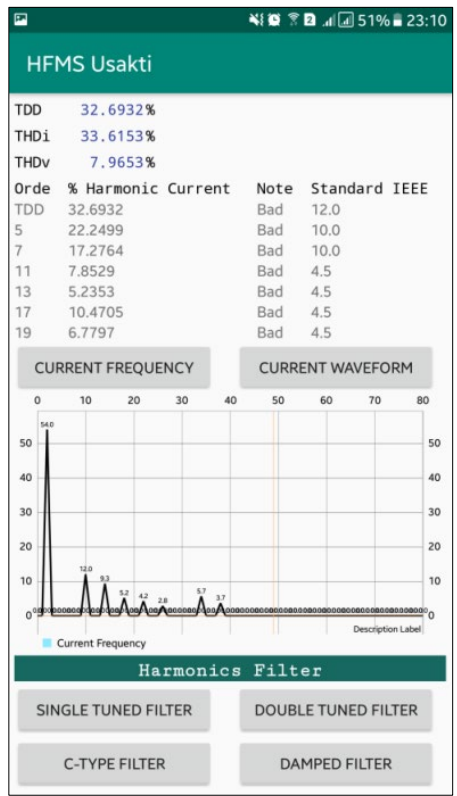

(b)

Figure 4. Comparison Harmonics Occured to The Standard.

(a) Current Waveform. (b) Current Amplitude/Frequency.

According to the Equation (1), current waveform in Figure 4.a in Android programming language can be coded as shown in the Appendix A.

Whilst, the current amplitude in Figure 4.b following the Equation 2 in Android programming language can be coded as shown in the Appendix B.

2) Calculating the parameters of Passive Filter

HFMS Usakti is limited in calculating four kinds of Filters. Thus, from the Interface of HFMS Usakti in Figure 4, there are four buttons of four kinds of filters (Single Tuned Filter, Double Tuned Filter, C-type Filter, and Damped-type Filter) that allow engineer to open a new interface of parameter calculation of the filter that has been selected. Eachfilter has their own interface for calculating their parameter as shown in Figure 5. 


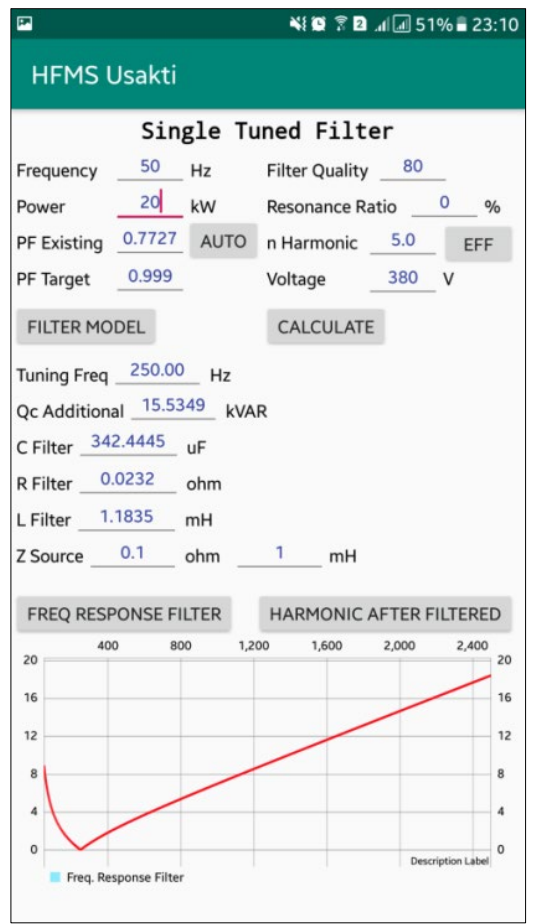

(a)

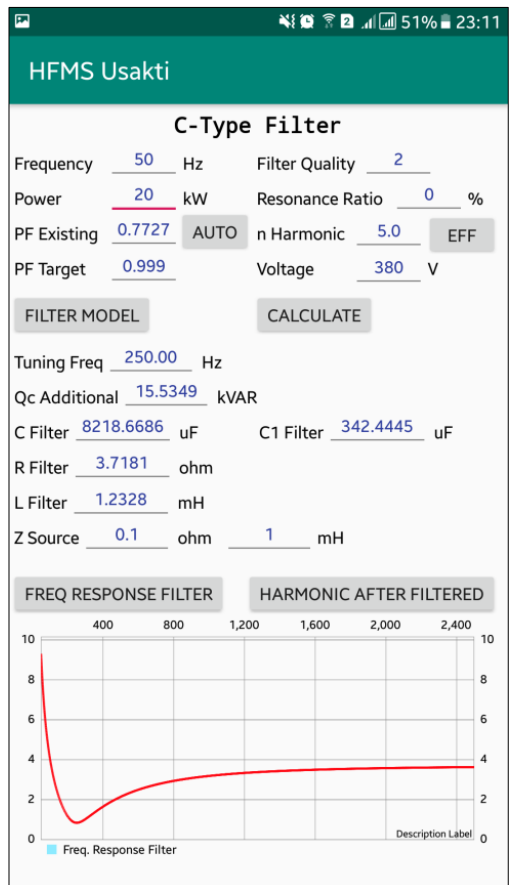

(c)

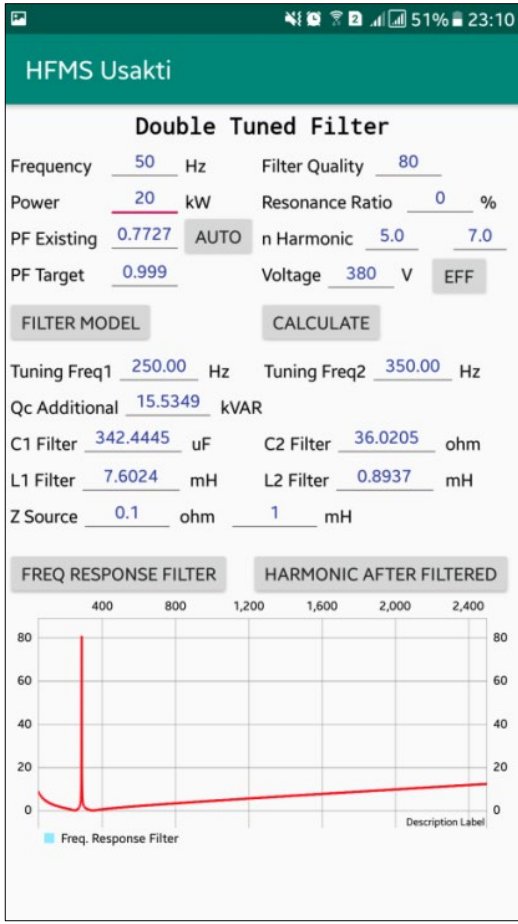

(b)

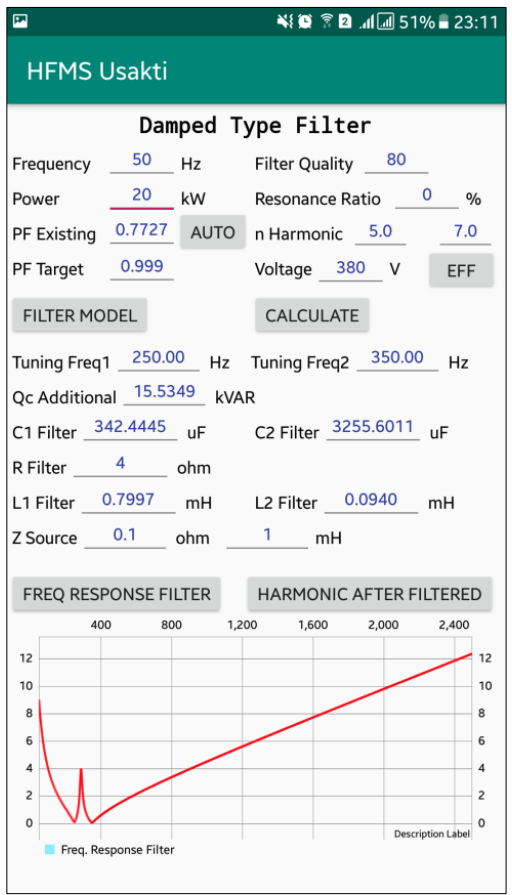

(d)

Figure 5. (a) Interface of Submenu Single Tuned Filter. (b) Interface of Submenu Double Tuned Filter. (c) Interface of Submenu C-Type Filter. (d) Interface of Submenu Damped Type Filter. 
Initially, engineer has to input other measured parameters such as active power and power factor (PF). HFMS is able toautomatically calculate PF initial by pressing the "Auto" button after active power has been inputted, this calculation based on Equation (3). nharmonic which will be suppressed can be also determined automatically by pressing "Eff" button, this determination based on the highest harmonic measured value which has been input in HFMS Usakti beforehand.

$$
T P F=\left(\frac{P}{\sqrt{3} \cdot V_{1} \cdot I_{1}}\right)\left(\frac{1}{\sqrt{\left(1+T H D_{v}^{2}\right)\left(1+T H D_{i}^{2}\right)}}\right)
$$

where $\mathrm{P}$ is an active power (Watt), $\mathrm{V}_{1}$ is fundamental voltage (Volt), $\mathrm{I}_{1}$ is fundamental current (Ampere), $\mathrm{THD}_{\mathrm{v}}$ is Total Harmonic Distortion Voltage, and $\mathrm{THD}_{\mathrm{i}}$ is Total Harmonic Distortion Current. Before developing Equation (3), the author has tried to follow Equation from Reference [15], but the Equation indicates invalid result when validation process is being conducted. Equation (3) in Android programming language can be shown in the Appendix C.

This paper also develops impedance equation for each filter used in HFMS Usakti. Equation (4) to Equation (7) shows the impedance equation of Single Tuned Filter, Double Tuned Filter, C-Type Filter and Damped Type Filter respectively.

$$
\begin{aligned}
& Z=\sqrt{R^{2}+(\omega L-1 /(\omega C))^{2}} \\
& Z=\left|\frac{J\left(\omega^{2} L_{1} L_{2}-\frac{L_{2}}{C_{2}}\right)}{\omega L_{1}+\omega L_{2}-\frac{1}{\omega C_{2}}}-J \frac{1}{\omega C_{1}}\right| \\
& Z=\sqrt{\left(\frac{R\left(\omega^{2} L C-1\right)^{2}}{(R \omega C)^{2}+\left(\omega^{2} L C-1\right)^{2}}\right)^{2}+\left(\frac{R^{2} \omega C\left(\omega^{2} L C-1\right)}{(R \omega C)^{2}+\left(\omega^{2} L C-1\right)^{2}}-\frac{1}{\omega C_{1}}\right)^{2}} \\
& Z=\sqrt{\left(\frac{\frac{L_{2}{ }^{2} R}{C_{2}{ }^{2}}}{\frac{L_{2}{ }^{2}}{C_{2}{ }^{2}}+\left(\omega L_{2} R-R / \omega C_{2}\right)^{2}}\right)^{2}+\left(\omega L_{1}-\left(\frac{\frac{L_{2} R}{C_{2}}\left(\omega L_{2} R-R / \omega C_{2}\right)}{\frac{L_{2}{ }^{2}}{C_{2}{ }^{2}}+\left(\omega L_{2} R-R / \omega C_{2}\right)^{2}}\right)-\frac{1}{\omega C_{1}}\right)^{2}}
\end{aligned}
$$

After developing impedance equation, the next step is to calculate filters parameter. For calculating the parameter of C-type filter follows Equation (8) - (12).

$$
\begin{aligned}
& Q=P \times\left\{\tan \left(\cos ^{-1} p f_{0}\right)-\tan \left(\cos ^{-1} p f_{1}\right)\right\} \\
& R=\frac{q U^{2}}{n Q} \\
& C=\frac{\left(n^{2}-1\right) Q}{\omega_{f} U^{2}} \\
& L=\frac{U^{2}}{\omega_{f}\left(n^{2}-1\right) Q} \\
& \left(\frac{1}{C_{1}}+\frac{1}{C}\right)^{-1}=\frac{\left(n^{2}-1\right) Q}{n^{2} \omega_{f} U^{2}}
\end{aligned}
$$

Before developing equation (12) above, the author has tried to follow Equation from Reference [18], but the Equation indicates invalid result when validation process is being conducted. To prove that there was a mistake from reference [18], author tried to made self development with the result as follows in Equation (13) to (20).

$$
\begin{aligned}
& C=C_{1}\left(n^{2}-1\right) \\
& C_{1}=\frac{Q}{\omega_{f} U^{2}} \\
& \frac{1}{C_{S}}=\frac{1}{C}+\frac{1}{C_{1}} \\
& \frac{1}{C_{S}}=\frac{1}{C_{1}\left(n^{2}-1\right)}+\frac{1}{C_{1}}
\end{aligned}
$$




$$
\begin{aligned}
& \frac{1}{C_{S}}=\frac{\left(n^{2}-1\right)+1}{C_{1}\left(n^{2}-1\right)} \\
& \frac{1}{C_{S}}=\frac{h_{0}{ }^{2}}{\frac{Q}{\omega_{f} U^{2}}\left(n^{2}-1\right)} \\
& \frac{1}{C_{S}}=\frac{n^{2} \omega_{f} U^{2}}{\left(n^{2}-1\right) Q} \\
& \left(\frac{1}{C_{1}}+\frac{1}{C}\right)^{-1}=\frac{\left(n^{2}-1\right) Q}{n^{2} \omega_{f} U^{2}}
\end{aligned}
$$

For calculating the parameter of single tuned filter follows Equation (8), (21) - (23).

$$
\begin{aligned}
& C=\frac{Q_{\text {com }}}{2 . \pi \cdot f \cdot U^{2}} \\
& R=\frac{(1+\epsilon)}{\left(q \omega_{h} C\right)} \\
& L=\frac{(1+\epsilon)^{2}}{\left(\omega_{h}^{2} C\right)}
\end{aligned}
$$

For calculation the parameter of double tuned filter parallel inductor follows Equation (8), (24) - (27).

$$
\begin{aligned}
C_{1}{ }^{\prime} & =C_{1} \\
L_{1}{ }^{\prime} & =\frac{L_{1}\left(L_{1}+L_{2}\right)}{L_{2}} \\
C_{2}{ }^{\prime} & =\frac{L_{2}^{2} C_{2}}{\left(L_{1}+L_{2}\right)^{2}} \\
L_{2}{ }^{\prime} & =L_{1}+L_{2}
\end{aligned}
$$

The calculation of parameter of damped-type double tuned filter is similar with double tuned filter but it uses a new algorithm to get the value of damping resistor [19]. Such kind of parameter filters above consist of $\mathrm{L}$ and $\mathrm{C}$ components. In fact, the value of $\mathrm{L}$ and $\mathrm{C}$ components which are used here have intention to make a system resonance, it will occur when $\mathrm{L}$ and $\mathrm{C}$ reactance are equal. Inductive reactance will raisewith increasing frequency and capacitive reactance will decrease with increasing frequency. When resonance occurs at tuned frequency, then the total impedance will increase to infinite. Using ohm's law, when impedance is infinite and voltage is unchanged, it will cause the current magnitude decrease to almost zero.

In the parameter calculation window, when "Calculate" button is pressed, HFMS will calculate filter parameter automatically based on measured data and then reveal them into text box. However, parameter value in the text box at window parameter calculation can be modified by engineer that allows them to get a desired value parameter. Every interface parameter calculation has "Freq. Response Filter" button that allows engineer to know the characteristiccurve of its filter. This shows that HFMS helps engineerfaster in calculating filters parameter and showing the filters frequency response. HFMS Usakti will also show a new interface of the filter diagram by pressing "Filter Model" button.

\section{3) Showing new harmonics value and new power factor after Filtering}

Reference [5] has informed that the single-line diagram of power system consists of non-linier loads and the bus which connected to the filter. That single-line diagram can be converted into single-phase equivalent circuit as shown in Figure 6. 


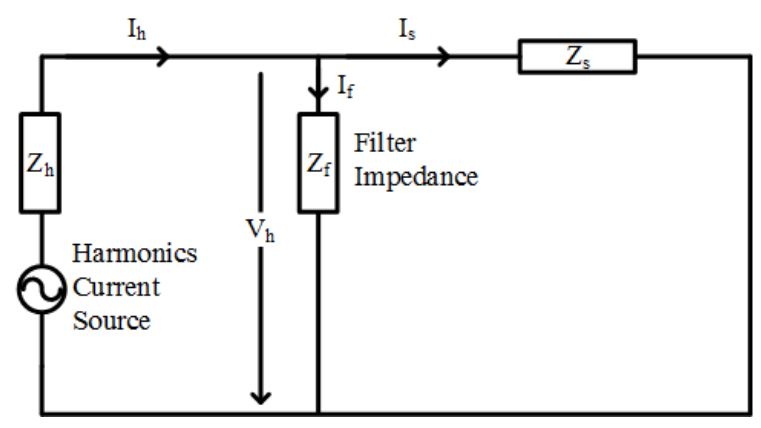

Figure 6. Single-phase Equivalent Circuit of Electrical Power System [5]

By taking into account its single-phase equivalent circuit given in Figure 6, the calculation of harmonic distortion after filtering can be calculated by following Equation (28).

$$
I_{S}=\left(\frac{z_{f}}{z_{f}+z_{s}}\right) I_{h}
$$

By using Equation (28), when the "Harmonic After Filtered" button on parameter calculation is pressed, it will show the graphic comparison between waveform before filtering in a red line and waveform after filtering in a green line. Then by using DFT Equation, harmonic distortion can be divided into its frequency component as shown in Figure 6. Each submenu of Filter calculation in Figure 4 has its own Sub interface of harmonics after filtering by clicking the "Harmonic After Filtered" button, Figure 7 below shows the interface of harmonics after filtering with Damped Type Filter.

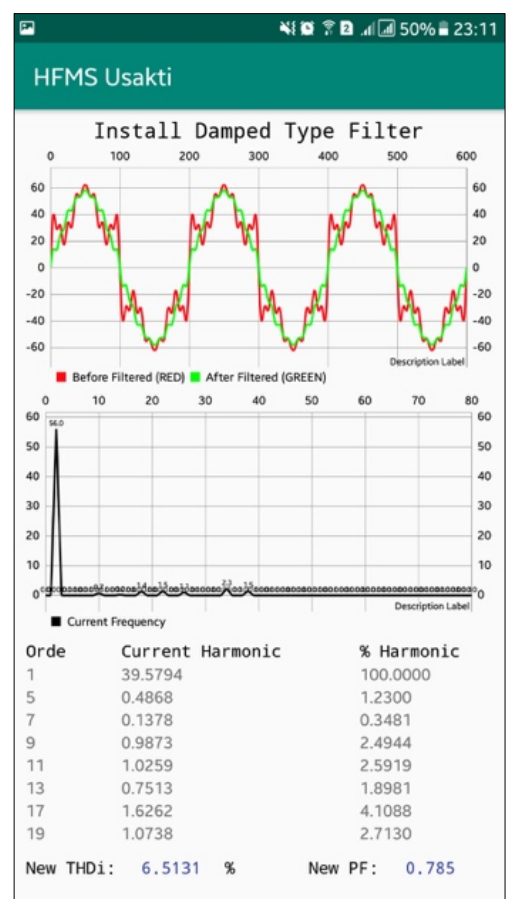

Figure 7. Interface of HFMS Usakti Waveform and Amplitude After Filtering with DFT

According to the Equation (28), the waveform of harmonics distortion after filtering in Figure 7 above, in Android programming language can be shown in the Appendix D. 
The result of simulation harmonic distortion after filtering can be represented into a table too, which not only shows the harmonic distortion each order but also shows the Total Harmonic Distortion and Power Factor after filtering. HFMS leads engineer to quickly find out the result of feasibility study, whether the filter does a well filtering or not. In addition, HFMS works either without drawing or making several equations, unlike other software programs do.

\section{Experimental and Testing}

Experimental and Testing in this research is conducted in two methods. First, the software validation using PSIM software. Second, the experimental using prototype (real experiment).

\section{A. Validation using PSIM software}

Software Validation has been conducted by using software PSIM. PSIM is one of many software programs that simulate power electronics and power system. The model of power system for validating HFMS is shown in Figure 8. The model is similar with digital simulation that has been conducted in reference [20] and block diagram of proposed method in reference [21].It is likened to the power system that engineer usually want to do feasibility study in real power system. Further, the measurement is conducted in PCC, a bus that needs to be installed the filter after feasibility study has been done.

The validation will be conducted by comparing harmonic distortion before filtering and after filtering by each filter (Single Tuned Filter, Double Tuned Filter, C-type Filter and Damped-type Filter), to make sure that HFMS works properly, the parameter of filter will be varied for looking a trend.

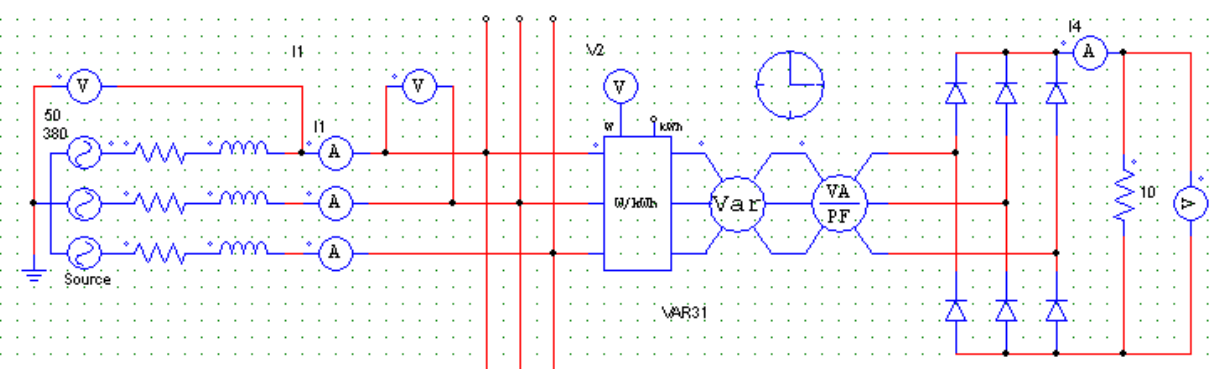

Figure 8. Model of Power System in PSIM for Validating HFMS

From Figure 8 above, the parameter of power system before filtering can be measured and written as shown in Table 5. While, the current harmonic distortion occurred before filtering and the voltage harmonic distortion occurred before filtering can be seen in Table 6 .

Table 5. Parameter of Power System

\begin{tabular}{|l|l|}
\hline \multicolumn{1}{|c|}{ Parameter } & \multicolumn{1}{c|}{ Value } \\
\hline $\mathrm{U}$ & $380 \mathrm{~V}$ \\
\hline $\mathrm{F}$ & $50 \mathrm{~Hz}$ \\
\hline $\mathrm{P}$ & $24,112556 \mathrm{~kW}$ \\
\hline Pf Existing & 0,9 \\
\hline R source & $0,1 \mathrm{Ohm}$ \\
\hline L source & $1 \mathrm{mH}$ \\
\hline I load & $39,28 \mathrm{~A}$ \\
\hline
\end{tabular}


Table 6. Current and Voltage Harmonic Distortion Occurred

\begin{tabular}{|l|l|l|l|l|l|l|l|}
\hline Order (n) & Fund & $\mathrm{h}_{5}$ & $\mathrm{~h}_{7}$ & $\mathrm{~h}_{11}$ & $\mathrm{~h}_{13}$ & $\mathrm{~h}_{17}$ & $\mathrm{~h}_{19}$ \\
\hline $\begin{array}{l}\text { Measured data of Current Harmonics } \\
\text { Distortion (A) }\end{array}$ & 38,2 & 8,46 & 3,36 & 2,24 & 1,24 & 0,86 & 0,46 \\
\hline $\begin{array}{l}\text { Measured data of Voltage Harmonics } \\
\text { Distortion (V) }\end{array}$ & 369,6 & 23,0 & 12,8 & 14,6 & 8,8 & 7,9 & 4,8 \\
\hline
\end{tabular}

\section{1) Comparing Harmonics Distortion Occurred Before Filtering}

In this testing stage, the comparison of harmonics measured data before filtering and simulation in HFMS Usakti will be conducted. The first step is to insert all measured parameters to HFMS Usakti.

HFMS Usakti is capable to input the exact number of harmonics occurred in power system. The intention is to minimize an inaccurate result, which if the beginning is not correct then the result will be more incorrect. The simulation of harmonics occurred in HFMS Usakti can be seen in Table 7 for current harmonics distortion and Table 8 for voltage harmonics distortion.

Table 7. Comparison between Measured Data and Simulation of Harmonics Current in HFMS

\begin{tabular}{|l|c|c|c|c|c|c|c|}
\hline \multicolumn{1}{|c|}{ Order (n) } & Fund & $\mathrm{h}_{5}$ & $\mathrm{~h}_{7}$ & $\mathrm{~h}_{11}$ & $\mathrm{~h}_{13}$ & $\mathrm{~h}_{17}$ & $\mathrm{~h}_{19}$ \\
\hline $\begin{array}{l}\text { Measured data of Current } \\
\text { Harmonics Distortion (A) }\end{array}$ & 38,2 & 8,46 & 3,36 & 2,24 & 1,24 & 0,86 & 0,46 \\
\hline $\begin{array}{l}\text { Simulation value of Current } \\
\text { Harmonics Distortion in HFMS } \\
\text { Usakti (A) }\end{array}$ & 38,2 & 8,46 & 3,36 & 2,24 & 1,24 & 0,86 & 0,46 \\
\hline $\begin{array}{l}\text { Deviation between Measured data } \\
\text { VS Simulation value }\end{array}$ & $0 \%$ & $0 \%$ & $0 \%$ & $0 \%$ & $0 \%$ & $0 \%$ & $0 \%$ \\
\hline
\end{tabular}

Table 8. Comparison between Measured Data and Simulation of Harmonics Voltage in HFMS

\begin{tabular}{|l|c|c|c|c|c|c|c|}
\hline \multicolumn{1}{|c|}{ Order (n) } & Fund & $\mathrm{h}_{5}$ & $\mathrm{~h}_{7}$ & $\mathrm{~h}_{11}$ & $\mathrm{~h}_{13}$ & $\mathrm{~h}_{17}$ & $\mathrm{~h}_{19}$ \\
\hline $\begin{array}{l}\text { Measured data of Voltage } \\
\text { Harmonics Distortion (V) }\end{array}$ & 369,6 & 23,0 & 12,8 & 14,6 & 8,8 & 7,9 & 4,8 \\
\hline $\begin{array}{l}\text { Simulation value of Voltage } \\
\text { Harmonics Distortion in HFMS } \\
\text { Usakti (V) }\end{array}$ & 369,6 & 23,0 & 12,8 & 14,6 & 8,8 & 7,9 & 4,8 \\
\hline $\begin{array}{l}\text { Deviation between Measured data } \\
\text { VS Simulation value }\end{array}$ & $0 \%$ & $0 \%$ & $0 \%$ & $0 \%$ & $0 \%$ & $0 \%$ & $0 \%$ \\
\hline
\end{tabular}

From Table 7 and Table 8 above proved that HFMS Usakti is capable to conduct simulation before filtering with result that exact with the measured data and no deviation. It is very different compare with Table 1, Table 2, Table 3, Table 4 which the research above used some commercial products such as ETAP and Matlab and the result of the result above have a wide range of deviation that can lead into inaccurate result of feasibility study.

\section{2) Comparing Result Harmonics Distortion After Filtering}

Before comparing the result harmonics distortion after filtering, it is conducted a comparison between the harmonics measured and harmonics standard. The comparison has been validated. Also, the calculation of filter parameter has also validated but it is not elaborated in this paper. This validation is more focus on the simulation of HFMS Usakti after filtering. 


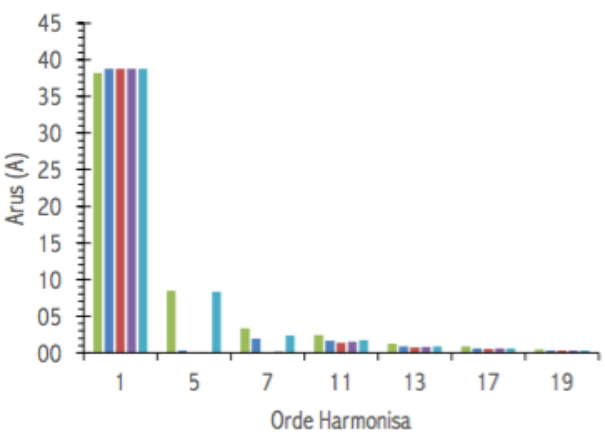

$$
\begin{aligned}
& =\text { Before } \\
& =\text { STF } \\
& =\text { DTF } \\
& \text { - Damped } \\
& =\text { Type-C }
\end{aligned}
$$

(a)

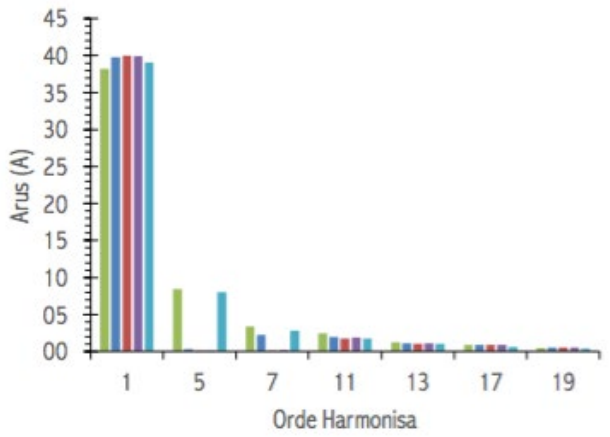

$$
\begin{aligned}
& =\text { Before } \\
& - \text { STF } \\
& \text { - DTF } \\
& - \text { Damped } \\
& =\text { Type-C }
\end{aligned}
$$

(b)

Figure 9. (a) Comparison Harmonics Distortion Before and After Filtering in PSIM. (b)

Comparison Harmonics Distortion Before and After Filtering in HFMS

Figure 9a shows the data of harmonics distortion before and after filtering from model power system in PSIM. Figure 9b shows the data of harmonics distortion before and after filtering from model power system in HFMS Usakti. In outline, from Figure $9 \mathrm{a}$ and $9 \mathrm{~b}$ can be concluded that HFMS Usakti works very well and can be used to simulate harmonics distortion based on measured data. The trend may look a bit different and need further research in the section of harmonics voltage to tackle the issue. Furthermore, HFMS Usakti needs to be developed in further research using database to make a feasibility study easier.

\section{B. Real Experiment (Using prototype)}

In this experimental testing, this research used energy-saving lamp as a non-linear load (source of harmonics distortion). The configuration and measurement can be shown as a Figure 10 below.

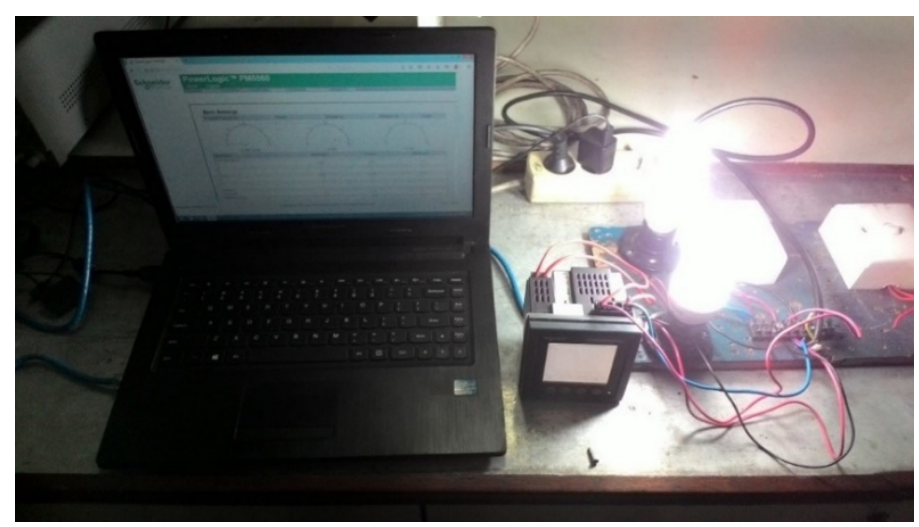

Figure 10. Configuration and Measurement of Non-Linear Load (Energy-Saving Lamps). 
Chairul Gagarin Irianto, et al.

From Figure 10 above, the measured data of the electrical network that consist of two energysaving lamps can be written as below. Whilst, Figure 11 shows the measured data on non-linear load visually. In addition, the harmonics distortion occurred per order can be shown in Table 9.

$\begin{array}{ll}\text { Voltage }(\text { Vavg) } & =222,08 \mathrm{Volt} \\ \text { Current (Iavg) } & =262,41 \mathrm{~mA} \\ \text { Power (Ptotal) } & =0,037 \mathrm{~kW} \\ \text { Power factor }(\mathrm{PF}) & =0,636 \mathrm{Lead} \\ \text { THDi } & =99,367 \% \\ \text { THDv } & =3,6285 \%\end{array}$

Table 9. Harmonics Distortion Occurred per order of Non-Linear Load (Energy Saving Lamps).

\begin{tabular}{|c|c|c|}
\hline Order & THDi (A) & THDi (\%) \\
\hline 3 & 0.204680 & 78 \\
\hline 5 & 0.118085 & 45 \\
\hline 7 & 0.076099 & 29 \\
\hline 9 & 0.062978 & 24 \\
\hline 11 & 0.044610 & 17 \\
\hline 13 & 0.031489 & 12 \\
\hline 15 & 0.036737 & 5 \\
\hline 17 & 0.031489 & 2,5 \\
\hline 19 & 0.013121 & 3,5 \\
\hline
\end{tabular}
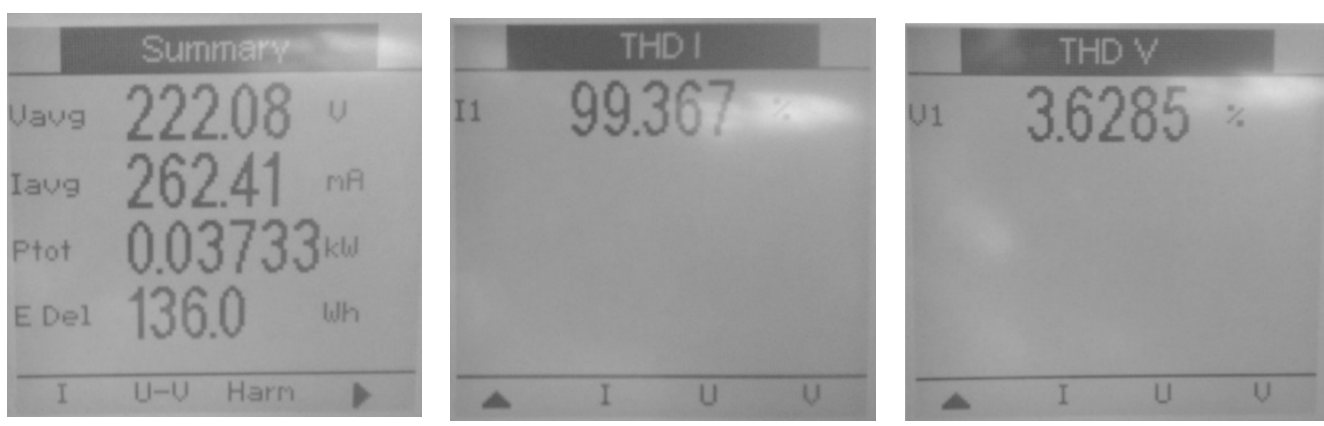

Figure 11. Measured Data of Non-Linear Load (Energy Saving Lamps).

From the data have collected above, then input all data into Android software HFMS Usakti. It is directly can be seen the result of comparison the harmonics occurred with the standard IEEE 519 ${ }^{\mathrm{TM}}-2014$ after the "Calculate" button is pressed. It lets the engineer and researcher to know quickly, whether the electrical network is in good or bad condition base on the standard. The checking result can be shown in Figure 12. 


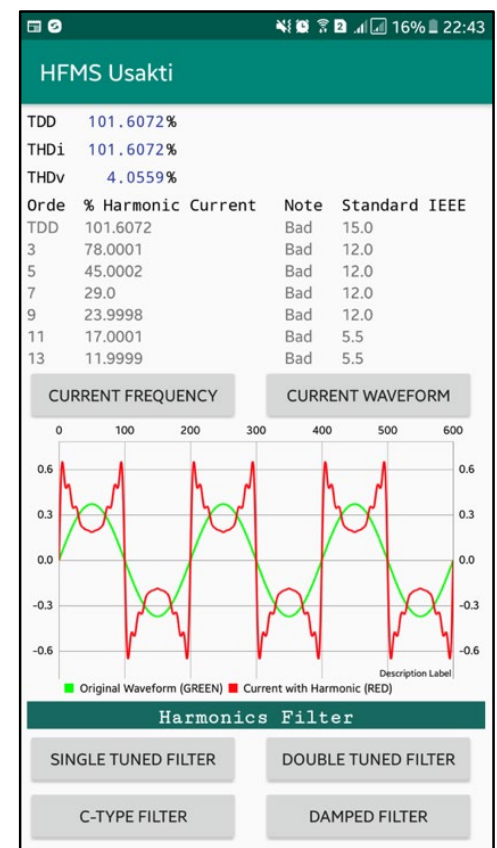

Figure 12. The Checking Result of Non-Linear Load (Energy Saving Lamps).

Figure 12 above shows that the harmonics distortion in the non-linear load of energy-saving lamps are very high, THDi $101 \%$ and THDv $4 \%$. When checking the standard, it is found that the harmonics distortion values in each order of the non-linear load are categorized as "Bad", which is outside the standard (not meet the standard threshold) IEEE 519 ${ }^{\mathrm{TM}}-2014$. It can also be seen that the sinusoidal waveform is no longer shaped like a pure sinusoidal wave, but there are ripples. The comparison between measured data and simulation in HFMS Usakti can be seen in Table 10.

Table 10.The Comparison between Measured Data and Simulation in HFMS Usakti.

\begin{tabular}{|l|c|c|c|c|c|c|c|}
\hline \multicolumn{1}{|c|}{ Order (n) } & THDi & $\mathrm{h}_{3}$ & $\mathrm{~h}_{5}$ & $\mathrm{~h}_{7}$ & $\mathrm{~h}_{9}$ & $\mathrm{~h}_{11}$ & $\mathrm{~h}_{13}$ \\
\hline $\begin{array}{l}\text { Measured data of Current } \\
\text { Harmonics Distortion (\%) }\end{array}$ & 99,367 & 78 & 45 & 29 & 24 & 17 & 12 \\
\hline $\begin{array}{l}\text { Simulation value of Current } \\
\text { Harmonics Distortion in HFMS } \\
\text { Usakti (\%) }\end{array}$ & 101,61 & 78 & 45 & 29 & 24 & 17 & 12 \\
\hline $\begin{array}{l}\text { Deviation between Measured data } \\
\text { VS Simulation value }\end{array}$ & $2,2 \%$ & $0 \%$ & $0 \%$ & $0 \%$ & $0 \%$ & $0 \%$ & $0 \%$ \\
\hline
\end{tabular}

From Table 10above shows that almost all data are same between the measured data and simulation in HFMS Usakti, there is only a slight difference in THDi result. It is very different compare with Table 1, Table 2, Table 3, Table 4which the research above used some commercial products such as ETAP and Matlab and the result of the result above have a wide range of deviation that can lead into inaccurate result of feasibility study.

Measured data indicates that PCC has THDi 99,367\% whilst the result of HFMS Usakti simulates THDi as $101,6072 \%$. This difference may be due to the inputted data on fundamental current in the HFMS Usakti using measured data of Average Current (Iavg) instead of fundamental current $\left(\mathrm{h}_{1}\right)$, because the meter can not display the fundamental current of the system. 


\title{
5. Conclusion and Future Work
}

Although a lot of software programs have been developed for feasibility study in harmonics phenomenon. However, those software programs only provide harmonics data of power electronics from their library and can't represent the real harmonics happened from real condition on power system. Feasibility study has to be conducted with measured data which represents real condition on power system so that it will create a precise calculation of filter parameters.

This way it can support the filter to suppress harmonics distortion at the tuned frequency on power system. This paper aims to assist engineering gaining a more accurate feasibility study using measured data by developing a new software namely HFMS Usakti. HFMS Usakti is a particular software which has the capacity to simulate harmonics distortion based on measurement data of harmonics current and harmonics voltage in the power system at the field.

HFMS Usakti is capable to compare the measured data with the harmonics limits based on standard IEEE 519 ${ }^{\mathrm{TM}}-2014$. This application has ability to calculate four kinds of harmonics passive filters (single tuned filter, double tuned filter, damped-type filter, and c-type filter) automatically based on measurement data. In addition, this Android application is also suitable to simulate the effect after the filter is installed into the power system (after filtering). The validation result indicates that HFMS Usakti is capable to make a simulation based on measured data from real condition in the field, and HFMS Usakti has similar trend with PSIM and HFMS works properly. The trend may look a bit different and need further research in the section of harmonics voltage to tackle the issue.

As currently HFMS Usakti has a limitation feature such as HFMS Usakti is not able to combine several filters at once simulation to reach the best performance of suppressing, it is planned for future work to add this feature.

\section{Acknowledgement}

The authors are very grateful to Universitas Trisakti (Trisakti University) for awarding them the research fund in the academic year 2019/2020 for this research.

\begin{abstract}
APPENDIX A
Math.sqrt (2)*(a1*Math.sin $(50 * h 1 * 2 *$ Math.PI*sineValues $[0][i])+a 2 *$ Math.sin $(50 * h 2 * 2 *$ Math $. P I *$ sineValues $[0][i])+a 3 *$ Math.sin $(50 * h 3 * 2 *$ Math.PI*sineValues [0] [i] $)+a 4 *$ Math. $\sin (50 * h 4$ $* 2 *$ Math.PI*sineValues [0] [i] $)+a 5 *$ Math.sin $(50 * h 5 * 2 *$ Math.PI*sineValues [0] [i] $)+a 6 *$ Math.s in $(50 * h 6 * 2 *$ Math.PI*sineValues [0] [i] $)+a 7 *$ Math.sin $(50 * h 7 * 2 *$ Math.PI*sineValues [0] [i] $)+a$ $8 *$ Math.sin $(50 * h 8 * 2 *$ Math.PI*sineValues [0] [i] $)+a 9 *$ Math.sin $(50 * h 9 * 2 *$ Math.PI*sineValues[ $0][i])+a 10 *$ Math.sin $(50 * h 10 * 2 *$ Math.PI*sineValues [0] [i] $)+a 11 *$ Math.sin $(50 * h 11 * 2 *$ Math.P $I *$ sineValues $[0][i])+$ a $12 *$ Math.sin $(50 * h 12 * 2 *$ Math.PI*sineValues [0] [i] $)+$ al $3 *$ Math $\sin (50 * h$ $13 * 2 *$ Math.PI*sineValues [0][i] $)+$ a $14 *$ Math.sin $(50 * h 14 * 2 *$ Math.PI*sineValues [0] [i] $)+$ al $5 *$ Math.sin $(50 * h 15 * 2 *$ Math.PI*sineValues [0] [i] $)+$ al $6 *$ Math.sin $(50 * h 16 * 2 *$ Math.PI*sineValue $s[0][i])+a 17 *$ Math.sin $(50 * h 17 * 2 *$ Math.PI*sineValues $[0][i])+$ a $18 *$ Math.sin $(50 * h 18 * 2 *$ Math .PI*sineValues [0] [i] $)+a 19 *$ Math.sin $(50 * h 19 * 2 *$ Math.PI*sineValues [0] [i] $)+$ a20*Math.sin(50 $* h 20 * 2 *$ Math.PI*sineValues [0][i]));
\end{abstract}

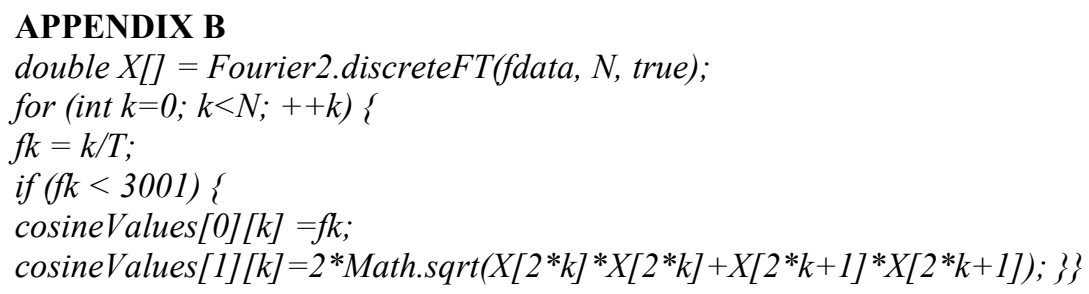




\title{
APPENDIX C
}

(power*1000/((Math.sqrt(3))*arusfunda*voltagefunda $)) *(1 /($ Math.sqrt $((1+($ thd $v *$ thd $v)) *(1+(t$ hdi*thdi)))));

\author{
APPENDIX D \\ Math.sqrt(2)*(((Math.sqrt(Math.pow((Math.PI*2*50*h1*l1-(1/(Math.PI*2*50*h1*c1))- \\ $((r *$ Math.PI* $2 * 50 * h 1 * l 2-$ \\ $(r /($ Math.PI*2*50*h1*c2)) $* r * l 2 / c 2) /((l 2 * l 2 /(c 2 * c 2))+(r *$ Math.PI*2*50*h1*l2- \\ $(r /($ Math.PI* $2 * 50 * h 1 * c 2))) *(r *$ Math.PI* $2 * 50 * h 1 * l 2-$ \\ $(r /($ Math.PI* $2 * 50 * h 1 * c 2))))), 2)+$ Math.pow $(((r * l 2 * l 2 /(c 2 * c 2)) /((l 2 * l 2 /(c 2 * c 2))+(r *$ Math.PI*2 \\ $* 50 * h 1 * l 2-(r /($ Math.PI* $2 * 50 * h 1 * c 2))) *(r *$ Math.PI* $2 * 50 * h 1 * l 2-$ \\ $(r /($ Math.PI*2*50*h1*c2))))),2)))/(Math.sqrt(Math.pow $(($ Math.PI*2*50*h1*(l1+lbebannya)- \\ $(1 /($ Math.PI* $2 * 50 * h 1 * c 1))-((r *$ Math.PI*2*50*h1*l2- \\ $(r /($ Math.PI* $2 * 50 * h 1 * c 2))) * r * l 2 / c 2) /((l 2 * l 2 /(c 2 * c 2))+(r *$ Math.PI* $2 * 50 * h 1 * l 2-$ \\ $(r /($ Math.PI* $2 * 50 * h 1 * c 2))) *(r *$ Math.PI* $2 * 50 * h 1 * l 2-$ \\ $(r /($ Math.PI* $2 * 50 * h 1 * c 2))))), 2)+$ Math.pow $(l b+((r * l 2 * l 2 /(c 2 * c 2))) /((l 2 * l 2 /(c 2 * c 2))+(r * M a t h . P$ \\ $I * 2 * 50 * h 1 * l 2-(r /($ Math.PI* $2 * 50 * h 1 * c 2))) *(r *$ Math.PI*2*50*h1*l2- \\ $(r /($ Math.PI*2*50*h1*c2))))),2))) $) * a 1 *$ Math.sin $(50 * h 1 * 2 *$ Math.PI*sineValues [0] [i])
}

\section{References}

[1]. Roger C. Dugan, Mark F. McGranaghan, Surya Santoso, and H. Wayne Beaty, "Electrical Power System Quality," McGraw-Hill, 2004.

[2]. M.T. Bishop, J.F. Baranowski, D. Heath, S.J. Benna "Evaluating Harmonic-Induced Transformer Heating," IEEE Transactions on Power Delivery, 1996, pp. 305-311.

[3]. R.A. Barr, V.J. Gosbell, "Power System Harmonic Voltage Limits for the Future," IEEE $16^{\text {th }}$ ICHQP, 2014, pp. 483-487.

[4]. K.D. Patil, W.Z. Gandhare, "Effects of Harmonics in Distribution Systems on Temperature Rise and Life of XLPE Power Cables," IEEE $15^{\text {th }}$ Students Conference on Researched and Development (SCOReD), 2017.

[5]. S. Sakar, A. D. Karaoglan, M. E. Balci, S. H. E. Abdel Aleem and A. F. Zobaa, "Optimal design of single-tuned passive filters using Response Surface Methodology". 2015 International School on Nonsinusoidal Currents and Compensation (ISNCC), Lagow, 2015, pp. 1-6.

[6]. Ying-Tung Hsiao. "Design of Filters for Reducing Harmonic Distortion and Correctiong Power Factor in Industrial Distribution Systems". Tamkang Journal of Science and Engineering, 2001, pp. 193-199 Vol. 4.

[7]. Xiangqian Tong, Junyi Xue, Wenjun Wu and Jie Li, "Approach of optimal tuning frequency in single tuned harmonic filter". Fourtieth IAS Annual Meeting. Conference Record of the 2005 Industry Applications Conference, 2005, hlm. 1888-1892 Vol. 3.

[8]. G. Li, X. Chen and C. Jin, "Modeling the single tuned passive harmonic filter based on the fractional calculus".Intl Conference on Industrial Electronics and Applications (ICIEA), Auckland, 2015, hlm. 1992-1994.

[9]. Mingcai Kang and Xinzhou Dong, "The parameters calculation and simulation research of two-types double-tuned filter" IEEE Transmission and Distribution Conference \& Exposition: Asia and Pasific, 2009.

[10]. HE Yi-hong, SU Heng."A New Method of Designing Double-tuned Filter". Intl Conference on Computer and Electronics Engineering, 2013.

[11]. M. A. Zamani and M. Mohseni, "Damped-type double tuned filters design for HVDC systems". 2007 9th International Conference on Electrical Power Quality and Utilisation, Barcelona, 2007, pp. 1-6. 
[12]. Xiao Yao, Zhao Jie, Mao Shijie, "Theory of the design of C-type filter". 2004 11th International Conference on Harmonics and Quality of Power, New York, USA, 2004, pp. 11-15.

[13]. dr inz. Ryszard Klempka. "A New Method for the C-Type Passive Filter Design". PRZEGLAD ELEKTROTECHNICZNY (Electrical Review), ISSN 0033-2097, R.88 NR 7a, 2012, pp. 277 - 281.

[14]. Yan Pang, Yonghai Xu, "Analysis and Treatment of Harmonic in Power Network with Railway based on ETAP Software," IEEE PES Asia-Pacific Power and Energy Conference (APPEEC), 2016, pp. 1424-1429.

[15]. Irshadi Izhhar,'Perancangan Filter Optimum untuk Mengatasi Efek Distorsi Harmonisa pada Gardu Traksi Kereta Rel Listrik (KRL) Stasiun Pasar Minggu,” Depok, 2014.

[16]. D. C. Bhonsle, R. B. Kelkar, "Harmonic Pollution Survey and Simulation of Passive Filter using MATLAB"," 2011 International Conference on recent Advancements in Electrical, Electronics and Control Engineering, Tamilnadu India, pp. 230-236.

[17]. IEEE, "IEEE Recommended Practice and Requirements for Harmonic Control in Electric Power Systems," IEEE Std 519 ${ }^{\mathrm{TM}}$-2014 (Revision of IEEE Std 519-1992), IEEE (The Institute of Electrical and Electronics Engineers). New York USA, 2014.

[18]. J. C. Das. Handbook: "Powers System Harmonics and Passive Filter Designs," Canada: John Wiley \& Sons. 2015

[19]. Haposan Yoga Pradika Napitupulu, Chairul Gagarin Irianto, “A New Algorithm for Designing the Parameter of Damped-Type Double Tuned Filter," International Conference on Electrical Engineering Computer Science and Informatics (EECSI), Malang Indonesia, 2018, pp. 175-179.

[20]. Amirullah, Adiananda, Ontoseno Penangsang, and Adi Soeprijanto, "Enhancing The Performace of Load Real Power Flow using Dual UPQC-Dual PV System based on Dual Fuzzy Sugeno Method", International Journal on Electrical Engineering and Informatics (IJEEI), Volume 13 Number 1, March 2021, pp. 21-56.

[21]. Anwar Muqorobin, Tri Desmana Rachmildha, Yanuarsyah Haroen, and Estiko Rijanto, "A Hybrid Controller for Boost Inverter: Modeling, Simulation, and Experimental Results", International Journal on Electrical Engineering and Informatics (IJEEI), Volume 13 Number 1, March 2021, pp. 179-190.

[22]. Satilmis URGUN and Halil YIGIT, "Selective Harmonic Eliminated Pulse Width Modulation (SHE-PWM) Method using Genetic Algorithm in Single-Phase Multilevel Inverters", International Journal on Electrical Engineering and Informatics (IJEEI), Volume 13 Number 1, March 2021, pp. 191-202.

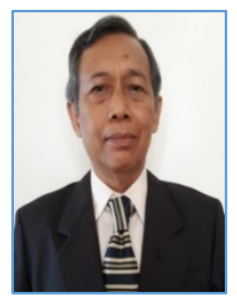

Chairul Gagarin Irianto was born in Surabaya, Indonesia in 1961. He received his bachelor degree in Electrical Engineering from Universitas Trisakti in 1986, the master degree from Institut Teknologi Bandung in 1992 and the doctor degree from Universitas Indonesia in 2010. He has been joining with the Department of Electrical Engineering, Universitas Trisakti since 1987 just one year after his graduation. His research interests include electrical machinery and power quality. Mr. Gagarin can be contacted at: chairul_irianto@trisakti.ac.id. 


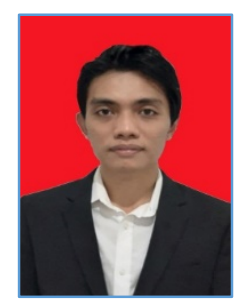

Haposan Yoga Pradika Napitupulu was born in Klaten, Indonesia in 1991. He received Associate (Diploma) Degree in electronics engineering from Politeknik Gajah Tunggal in 2014. He received Bachelor Degree in electrical power engineering from Universitas Trisakti in 2018. Besides being as a professional, $\mathrm{He}$ is involved with the department of electrical engineering Universitas Trisakti as a research assistant. He is pursuing scholarship for Master Degree. He can be contacted at haposan.ypn@outlook.com.

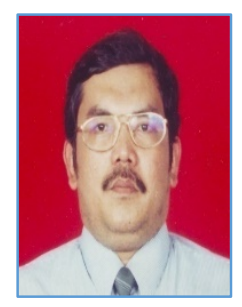

Maulasukma Widjaja was born in Bogor-West Java, Indonesia, in 1959. He holds a B.Eng in the Department of Electrical Engineering Trisakti and M.Eng in electrical engineering Bandung Institute of Technology (ITB), Indonesia, in 1984 and 1991, respectively. He is a researcher at electrical energy conversion research laboratory, Trisakti. Since 1985, he is a lecturer in the Department of Electrical Engineering, Trisakti. His research interests include power electronics, electrical machinery and Electrical Power Systems. Ir. Maulasukma Widjaja, MS can be reached at The Department of Electrical Engineering, Trisakti, Jl. Kiai Tapa Grogol No. 1, Indonesia 14440 or by email maula@trisakti.ac.id. 